\title{
BASES LEGAIS DO SUS NO CONSELHO MUNICIPAL: UM DESAFIO PARA EFETIVAR A GESTÃO PARTICIPATIVA NA SAÚDE
}

\author{
Maraisa Manorov \\ Universidade Federal da Fronteira Sul \\ mara_manorov@hotmail.com
}

Angela Maria Gomes

Universidade Federal da Fronteira Sul angela.mg92@gmail.com

Adriana Hilhesheim Universidade Comunitária da região de Chapecó adrianah@unochapeco.edu.br
Liane Colliselli

Universidade Federal da Fronteira Sul liane.colliselli@uffs.edu.br

Larissa Hermes Thomas Tombini Universidade Federal da Fronteira Sul larissa.tombini@uffs.edu.br

Valéria Silvana Faganello Madureira Universidade Federal da Fronteira Sul valeria.madureira@uffs.edu.br

\section{Resumo}

Trata-se de compartilhamento de resultados encontrados no desenvolvimento de um projeto de extensão intitulado "Educação Permanente para Conselheiros Municipais de Saúde: Macrorregião Oeste de Santa Catarina”. Período: segundo semestre de 2015. Objetivo: fortalecer, qualificar e instrumentalizar os conselheiros municipais de saúde, para o exercício de suas atribuições e competências. Método: foi desenvolvido em três módulos utilizando metodologias ativas para discutir participação social com ênfase na legislação do Sistema Único de Saúde. Resultados: identificou-se desconhecimento sobre a legislação do SUS, especialmente sobre o que define o funcionamento dos conselhos de saúde. Em razão disso, os participantes se envolveram e participaram nas discussões relacionando os temas com seu cotidiano. Conclusão: Constatou-se que é necessária e urgente a capacitação de conselheiros municipais de saúde para o exercício da sua função, em especial no que tange à legislação, o que implica de forma direta na sua responsabilidade na condição de conselheiro municipal de saúde.

Palavras-chave: Educação Continuada. Conselhos de Saúde. Participação Social. Sistema Único de Saúde.

\section{LEGAL BASIS OF THE MUNICIPAL COUNCIL SUS: A CHALLENGE TO EFFECT PARTICIPATORY MANAGEMENT HEALTH}

\begin{abstract}
This is a sharing of results found in the development of an extension project entitled "Permanent Education for Municipal Health Counselors: Western Macroregion of Santa Catarina". Period: second half of 2015. Objective: to strengthen, qualify and instrumentalize the municipal health counselors, in order to exercise their attributions and competencies. Method: it was developed in three modules using active methodologies to discuss social participation with emphasis on the legislation of the Unified Health System (SUS). Results: the lack of knowledge about SUS legislation was identified, especially on what defines the functioning of health councils. As a result, the participants got involved and participated in the discussions relating the themes to their daily lives. Conclusion: It was found that it is necessary and urgent the training of municipal health councilors to carry out their duties, especially with regard to legislation, which directly implies their responsibility as a municipal health counselor.

Keywords: Education Continuing. Health Councils. Social Participation. Unified Health System.

\section{FUNDAMENTO JURÍDICO DE LA SUS CONSEJO MUNICIPAL: UN RETO A EFECTO EN LA SALUD GESTIÓN PARTICIPATIVA}

\section{Resumen}

Se trata de compartir resultados encontrados en el desarrollo de un proyecto de extensión titulado "Educación Permanente para Consejeros Municipales de Salud: Macrorregión Oeste de Santa Catarina". Período: segundo semestre de 2015. Objetivo: fortalecer, calificar e instrumentalizar a los consejeros municipales de salud, para el ejercicio de sus atribuciones y competencias. Método: fue desarrollado en tres módulos utilizando metodologías activas para discutir participación social con énfasis en la legislación del Sistema Único de Salud. Resultados: se identificó desconocimiento sobre la legislación del SUS, especialmente sobre lo que define el funcionamiento de los consejos de salud. En consecuencia, los participantes se involucraron y participar en las discusiones relacionando los temas con su cotidiano. Conclusión: Se constató que es necesaria y urgente la capacitación de consejeros municipales de salud para el ejercicio de su función, en especial en lo que se refiere a la legislación, lo que implica de forma directa en su responsabilidad en la condición de consejero municipal de salud.

Palavras clave: Educación Continua. Consejos de Salud. Participación social. Sistema Único de Salud. 
Bases legais do SUS no conselho municipal: um desafio para efetivar a gestão participativa na saúde

\section{INTRODUÇÃO}

No Brasil, os primeiros movimentos de participação social junto à construção de políticas públicas de saúde ocorreram na década de 70, através de um movimento que ficou conhecido como Reforma Sanitária Brasileira. Impulsionado pela mobilização sanitarista inicial ocorreu, em 1986, a $8^{\text {a }}$ Conferência Nacional de Saúde, considerada marco de envolvimento da sociedade civil através dos movimentos sociais e de representatividade popular frente à construção de políticas para a saúde, que resultou na criação do Sistema Único de Saúde (SUS), instituído na Constituição Federal de 1988 (POLIGNANO, s/d; PAIM, 2012).

Foi por meio da promulgação da Constituição Federal em 1988 que a perspectiva de democracia representativa e participativa passa a incorporar a gestão das políticas públicas no Brasil (PAIM, 2012). Nesse contexto surgem fóruns de gestão de políticas públicas, em especial, os conselhos gestores municipais, que se configuram em espaços públicos de participação e articulação entre governo e sociedade, ante a responsabilização partilhada nessa gestão que passa a requerer dos sujeitos envolvidos um "fazer parte efetivo" no desencadear do processo de desenvolvimento político e social (KLEBA; ZAMPIROM; COMERLATTTO, 2015).

A Lei Orgânica da Saúde no 8.142 de 28 de dezembro de 1990, regulamentou o processo de inserção dos sujeitos na construção de políticas públicas e estabeleceu a participação da comunidade na sua gestão, através dos conselhos e conferências. No âmbito municipal, o conselho caracteriza-se como um pré-requisito obrigatório à municipalização, fazendo parte do sistema de decisões das políticas locais (BRASIL, 1990).

Assim, os espaços de gestão participativa, conselhos e conferências, se consolidam como forma inovadora de participação social na gestão das políticas públicas, caracterizando-se como espaços apropriados para o exercício de uma cidadania ativa (COLLISELLI, 2009).

O Conselho de Saúde é uma instância colegiada, deliberativa e permanente do SUS em cada esfera de governo (BRASIL, 2012). São espaços participativos de aproximação entre as instâncias governamentais e não governamentais promovendo a corresponsabilização entre estas, o diálogo, a contestação e a negociação a favor da democracia e da cidadania (BRASIL, 2006; 2009). Ainda, são instituídos na perspectiva de atuar na descentralização das ações e serviços de saúde, no controle do cumprimento de princípios e diretrizes do SUS e na promoção da participação da população em sua gestão (BRASIL, 2006; 2009). Contudo, entende-se que, além dos atores reconhecerem o seu papel como conselheiros, é preciso que saibam como exercê-lo e como participar do processo de construção dos instrumentos de gestão na área da saúde. 
Bases legais do SUS no conselho municipal: um desafio para efetivar a gestão participativa na saúde

Desta maneira, o próprio Conselho Nacional de Saúde (CNS) sinaliza, através da Política Nacional de Educação Permanente para o controle social no SUS (PNEPS-SUS), a necessidade de qualificar a participação social na formulação, gestão e controle social da política pública de saúde, visando o fortalecimento dos conselheiros e, por consequência, dos conselhos gestores de políticas públicas (BRASIL, 2009).

A participação social é um processo em permanente construção e, para que se concretize, é preciso instituir e fornecer condições para a democracia participativa acontecer na prática, ou seja, é preciso aproximar as informações dos atores que circulam por estes espaços (ROLIM; CRUZ; SAMPAIO, 2013). Nesse sentido, a PNEPS-SUS propõe a criação de Comissões Permanentes de Integração Ensino-Serviço (CIES) regionalizadas, formadas por gestores, trabalhadores do SUS, instituições de ensino, entidades representativas e movimentos sociais com o objetivo de fomentar ações de educação permanente em saúde (BRASIL, 2009). Atualmente em Santa Catarina, segundo o Plano Estadual de Educação Permanente em Saúde (2009), existem 15 polos regionais da CIES, entre eles o da Região Oeste, o qual assiste 27 municípios das regionais de saúde de Chapecó, Quilombo e Palmitos. Esses polos desenvolvem, entre outras, ações de educação permanente com o intuito de promover o fortalecimento do controle social (SANTA CATARINA, 2009) com ênfase na comunicação e no acesso à informação como prioritários ao fortalecimento desejado.

Neste contexto apresenta-se, ainda, o Programa de Inclusão Digital (PID) que objetiva contribuir para que os conselheiros de saúde "se apropriem de informações e adquiram habilidades para comunicação indispensáveis ao exercício do controle social" (FREITAS; SOUTO; BONETTI, 2012, p.2) através da disponibilização de equipamentos aos conselhos, conectividade e formação de conselheiros (FREITAS; SOUTO; BONETTI, 2012).

Dessa forma, considerando a necessidade de aprimoramento e, com objetivo de consolidar e fortalecer o processo de controle social no SUS, o Conselho Nacional de Saúde lança a Resolução n ${ }^{\circ} 453$ de 10 de maio de 2012, que estabelece as diretrizes para instituição, reformulação, reestruturação e funcionamento dos Conselhos de Saúde no Brasil (BRASIL, 2012).

Neste cenário surge o projeto de extensão "Educação Permanente para Conselheiros Municipais de Saúde: Macrorregião Oeste”, oriundo da parceria entre a Universidade Federal da Fronteira Sul (UFFS), a CIES regional, a Gerência Regional de Saúde de Chapecó e o Consórcio Intermunicipal de Saúde da Associação dos Municípios do Oeste de Santa Catarina (CISAMOSC), com vistas a fortalecer os Conselhos Municipais de Saúde na região do oeste catarinense. 
Bases legais do SUS no conselho municipal: um desafio para efetivar a gestão participativa na saúde

O presente artigo busca compartilhar os resultados positivos, desafiadores, motivadores e reflexivos de parte das atividades desenvolvidas. Ainda, objetiva refletir sobre a experiência de educação permanente com os Conselheiros Municipais de Saúde da região Oeste Catarinense acerca dos instrumentos e bases legais do SUS que permeiam o cotidiano desses colegiados.

\section{MÉTODOS}

O projeto envolveu 81 conselheiros municipais de saúde de 21 municípios da região Oeste Catarinense, no período entre julho e outubro de 2015. Os participantes foram organizados em três turmas de aproximadamente 27 conselheiros cada, com base nas regiões de abrangência das Secretarias de Desenvolvimento Regional (SDR - Chapecó, Quilombo e Palmitos), às quais os municípios pertencem.

Operacionalmente, a capacitação foi organizada em três módulos temáticos. O presente artigo abordará de maneira específica as atividades e reflexões do primeiro módulo, com ênfase no arcabouço legal do SUS e do controle social, utilizando-se da Constituição Federal de 1988, Lei no 8.080 de 19 de setembro de 1990, Lei no 8.142 de 28 de dezembro de 1990, Portaria $n^{\circ}$ 2.488 de 21 de outubro de 2011 e Resolução 453 de 10 de maio de 2012.

Por se tratar de uma ação de educação permanente com o intuito de fortalecer a participação social, ainda, considerando que entre os conselheiros municipais de saúde existe uma diversidade nas representações dos segmentos, uma ação desse tipo necessita de metodologias que sejam capazes de envolver todos e que reflitam sobre a realidade dos participantes. Nesse sentido, remetemos aos referenciais teóricos de Paulo Freire (1996) em que o saber fundado na prática educativa, considerando os diferentes saberes - algo que não seja estranho a educadores e educandos - valorizando a autonomia, a liberdade, criatividade e criticidade dos sujeitos envolvidos, está a forma ideal, em que os diferentes saberes se tornam sabedoria (FREIRE, 1996). Considerando as colocações acima, os encontros foram planejados e organizados com metodologias ativas e problematizadoras, conforme seguem descritas.

Para o desenvolvimento do Módulo I realizou-se um encontro presencial com duração de oito horas, com cada um dos três grupos organizados conforme a SDR de abrangência. Considerando a importância de interação, optou-se pelo método dialético de ensino e aprendizagem, que possibilita desenvolver o processo crítico e reflexivo acerca da temática: tempestade cerebral para a qual foram utilizadas tarjetas, atividades em pequenos grupos com rodas de conversas posteriores, recursos áudio visuais (multimídia), entre outros. 
Bases legais do SUS no conselho municipal: um desafio para efetivar a gestão participativa na saúde

Cada encontro iniciou com o reconhecimento da realidade dos participantes referentes a legislação, através de relatos, reflexões, apontamento de limites e possibilidades vivenciadas na sua trajetória de conselheiro de saúde.

Para dar inicio às atividades do Módulo I foi proposto a cada participante escrever em tarjetas o que compreendia sobre as seguintes palavras: SUS, Lei $\mathrm{n}^{\circ}$ 8080/90, Lei n ${ }^{\circ} 8142 / 90$, Portaria no 2.488/2011 e Resolução no 453/2012. Mesmo o fato de desconhecer a legislação ou não se lembrar do que a mesma aborda, tal indicativo deveria ser contemplado na tarjeta.

$\mathrm{Na}$ sequência, os participantes foram organizados em quatro grupos, onde cada um deveria executar duas tarefas, com base nas legislações acima mencionadas: 1. Falar e refletir sobre o que eu sei sobre a legislação. 2. Realizar a leitura e refletir no grupo a importância da legislação no desempenho das suas atribuições/competências no conselho.

Em seguida, os resultados das reflexões dos pequenos grupos foram socializados com o grande grupo originando muitas discussões e ponderações.

Ainda, no intuito de resgatar e ampliar a memória do SUS utilizou-se o documentário do Ministério da Saúde intitulado "Políticas de Saúde no Brasil: Um século de luta pelo direito à saúde” em recurso multimídia. Após, encaminhou-se a atividade de dispersão a ser realizada antes do próximo encontro, que consistia na busca e leitura dos instrumentos de gestão do município: Plano Municipal de Saúde (PMS), ata de aprovação do PMS junto ao conselho e o último relatório de gestão aprovado pelo conselho municipal de saúde.

Ao final, utilizou-se uma dinâmica para avaliar o módulo onde os participantes responderam a três itens: 'Que bom que', 'Que pena que' e 'Que tal se'. Através desta puderam expressar suas opiniões e sugestões para edições posteriores.

\section{RESULTADOS E DISCUSSÃO}

Os objetivos inicialmente propostos, de refletir com os participantes sobre a legislação vigente e, a partir disso, instrumentalizá-los para a sua atuação como Conselheiros Municipais de Saúde e o exercício da cidadania, foram amplamente atingidos. Identificou-se que existe conhecimento predominante à Lei $n^{\circ} 8.080 / 90$ e de aspecto mais limitado à Lei $n^{\circ}$ 8.142/90, conforme demonstram as figuras 1 e 2 , a seguir. 


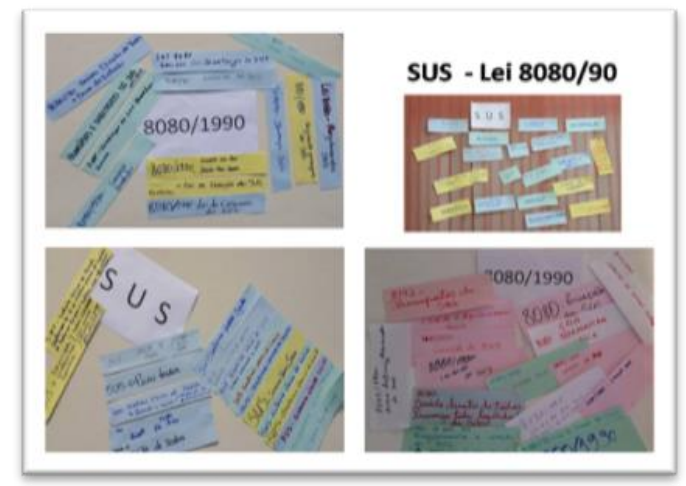

Figura 1: Conhecimento dos Conselheiros sobre a Lei no 8080/90. Chapecó, SC, 2015.

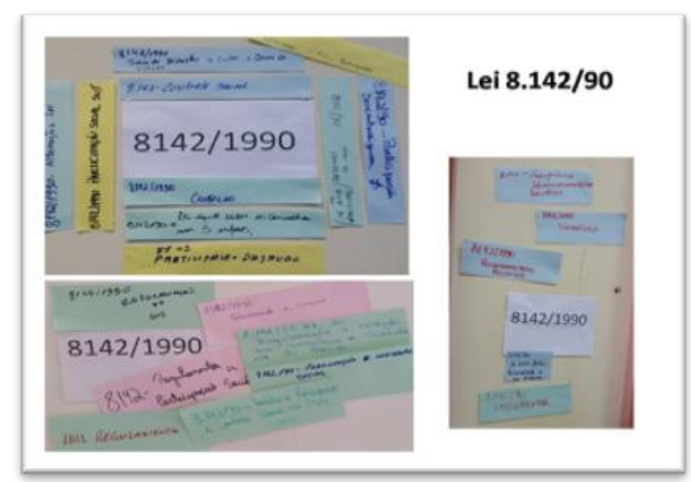

Figura 2: Conhecimento dos Conselheiros sobre a Lei no 8142. Chapecó, SC, 2015.

A técnica da "tempestade cerebral" organizada a partir das tarjetas possibilitou visualizar que muitos participantes apresentaram dificuldades para compreender a diferença entre as mesmas. Muitas vezes as descreveram como sinônimos e referenciando-as como "Diretrizes do SUS", "Saúde direito de todos e dever do Estado", "criação do SUS", "regulamentação do SUS", "participação do SUS”, “descentralização de recursos", "Lei que criou o conselho de saúde nas três esferas". Isso evidencia que os conselheiros apresentam limites em relação ao total conhecimento da legislação vigente, bem como da sua importância na gestão do SUS e da participação social.

Atualmente, estudos sinalizam uma preocupação com a baixa representatividade dos conselheiros ocasionada por falta de instrumentos e conhecimento, principalmente sobre a legislação normativa do SUS e na responsabilidade da sua função como conselheiros de saúde. Em seu estudo, Cotta et al (2009) perceberam a desinformação dos conselheiros de saúde em relação a seu papel como agentes deliberativos, assim como sobre o papel do próprio conselho municipal de saúde na esfera social e sanitária.

No decorrer da execução do projeto de extensão ora apresentado, observou-se situação semelhante à apontada por Cotta et al (2009), pois o acesso às informações referentes ao controle social ainda é pontual e cada conselheiro busca tais informações conforme sua necessidade e disponibilidade. Outra situação preocupante refere-se à indicação de representantes do controle social, haja vista muitos conselheiros são indicados sem ao menos serem informados sobre seu papel como representantes no conselho.

Considera-se que a efetivação de políticas públicas em saúde depende da melhoria da qualidade da representação social, bem como do acesso dos conselheiros às informações necessárias à sua atuação como cidadãos envolvidos com o controle social. Dessa forma, entende-se ser difícil exercer o controle social, deliberar, aprovar, fiscalizar ou propor qualquer ação se estes agentes desconhecem o arcabouço legal, as normatizações, as fontes de onde 
Bases legais do SUS no conselho municipal: um desafio para efetivar a gestão participativa na saúde

provêm os recursos financeiros que financiam o SUS, entre outros fundamentos à sua construção e controle.

Nesse sentido, ressalta-se a importância de ampliar espaços como os que aqui são relatados, a fim de desencadear um processo de empoderamento dos diferentes agentes $\mathrm{e}$ fortalecer o controle social. O papel desses representantes é atuar na formulação, proposição de estratégias e no controle da execução das políticas de saúde, inclusive nos seus aspectos econômicos e financeiros (BRASIL, 2012). Portanto, o desconhecimento dos conselheiros sobre tais legislações implicará diretamente na sua atuação. A esse respeito, Cotta et al (2009) salientam que o desconhecimento sobre seu papel limita a eficiência da atuação dos conselheiros no CMS.

Além da legislação normativa do SUS, foi apresentada e discutida a resolução regulamentadora dos conselhos de saúde no Brasil, Resolução no 453 de 10 de maio de 2012, que dispõe sobre a definição, a organização, a estrutura, o funcionamento e as competências do Conselho de Saúde. Observou-se, a partir da dinâmica (figura 3) que o desconhecimento acerca da mesma é significativo, que requer ações concretas urgentes na perspectiva de fortalecer e qualificar a participação social na gestão das políticas públicas.

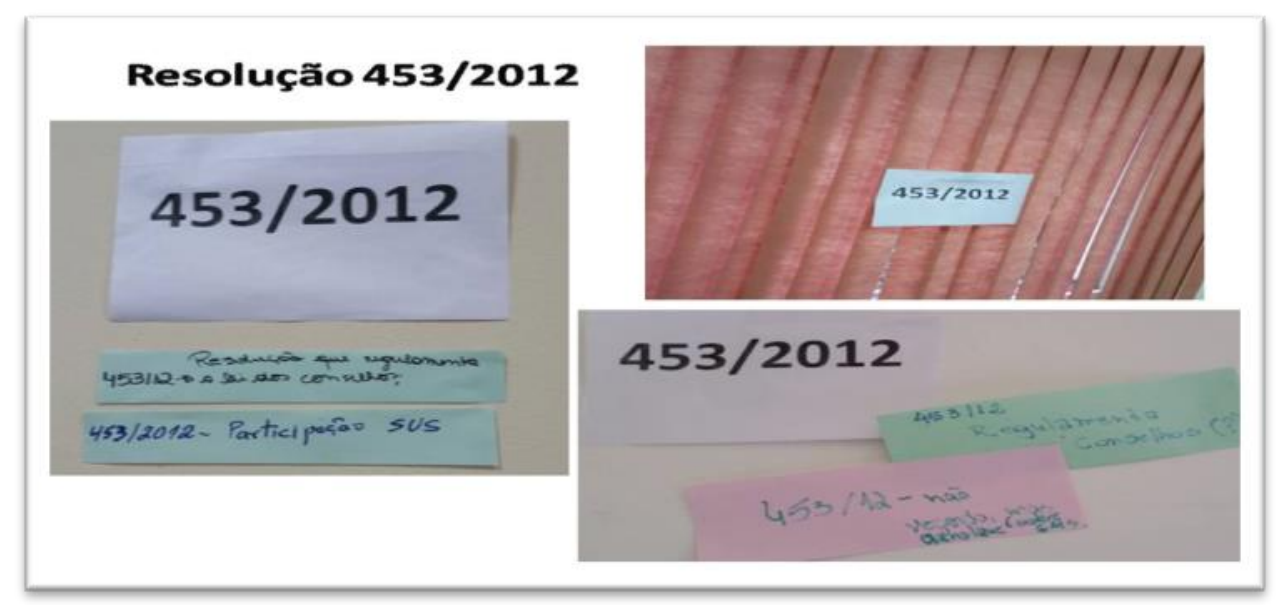

Figura 3: Conhecimento dos Conselheiros sobre a Resolução nº 453/2012. Chapecó, SC, 2015.

Durante a atividade de educação permanente reforçou-se o conteúdo desta resolução, resgatando inicialmente a definição do Conselho "órgão colegiado [...] que atua na formulação e proposição de estratégias e no controle da execução das Políticas de Saúde, inclusive nos seus aspectos econômicos e financeiros”. (RESOLUÇÃO 453/12, p.02). Compreender a definição de Conselho constitui requisito fundamental ao exercício do papel de conselheiro, que implicando diretamente no compromisso e responsabilidade destes junto ao conselho e sociedade.

Em relação à organização dos conselhos, se enfatizou a representação, considerando a paridade entre os três segmentos (usuários, profissionais e prestadores). Neste item muitos 
Bases legais do SUS no conselho municipal: um desafio para efetivar a gestão participativa na saúde

sinalizaram preocupação em relação à composição no seu conselho. Também foram motivados para falar sobre a periodicidade, a divulgação das reuniões, a renovação dos conselheiros, o encaminhamento da pauta, o exercício da presidência do conselho e de forma especial foram elencadas as competências/atribuições do conselho. Alguns itens destes foram resgatados nos encontros posteriores.

Durante os encontros, a maioria dos participantes referiu que a elaboração da pauta ocorre no dia da reunião, e não como preconiza a resolução na quarta diretriz, artigo IV: “[...] A pauta e o material de apoio às reuniões devem ser encaminhados aos conselheiros com antecedência mínima de 10 (dez) dias" (BRASIL, 2012). Esse fator impossibilita que os conselheiros estejam preparados para argumentar, questionar e se posicionar sobre os temas abordados nas reuniões, bem como discutir previamente com os seus representados/pares.

Estudos realizados por Rocha (2011, p. 178) demonstram que essa fragilidade é realidade de outros conselhos no Brasil, nos quais assuntos tratados no conselho são definidos sem maior planejamento e discussão. A esse respeito, Cotta, Cazal e Rodrigues (2009, p.433) declaram que, no âmbito do controle social, é essencial ter acesso à informação, pois "expande a capacidade de argumentação dos conselheiros nos processos decisórios”, o que amplia a possibilidade de deliberação sobre a política de saúde e de intervenção na realidade (COTTTA; CAZAL; RODRIGUES, 2009, p. 433).

A renovação periódica da composição dos membros do conselho foi outro ponto de destaque abordado na formação. A Resolução no 453/2012 recomenda que, a cada eleição, cada segmento promova uma renovação de, no mínimo, 30\% de suas entidades representativas. Muitos manifestaram desconhecimento sobre esse apontamento legal, que direta ou indiretamente influenciam nas tomadas de decisões dentro destes órgãos.

Ainda, em uma das três turmas de capacitação, alguns conselheiros manifestaram a importância do conselho ser um órgão independente da gestão (governos municipais e ou estadual). Essa fala vinda dos próprios participantes sinaliza que apesar do significativo desconhecimento das bases legais, estes possuem expressiva consciência sanitária e cidadã. Afinal, considera-se que essa independência política é o que garante que os conselhos reflitam e tomem decisões e atendam às reais necessidades em saúde da população.

Durante o processo de capacitação também se contemplou a Política Nacional da Atenção Básica (PNAB). Quando visualizavam a tarjeta referente à Portaria no 2.488/2011, a maioria dos participantes manifestou não possuir conhecimento sobre ela, conforme figura 4. 


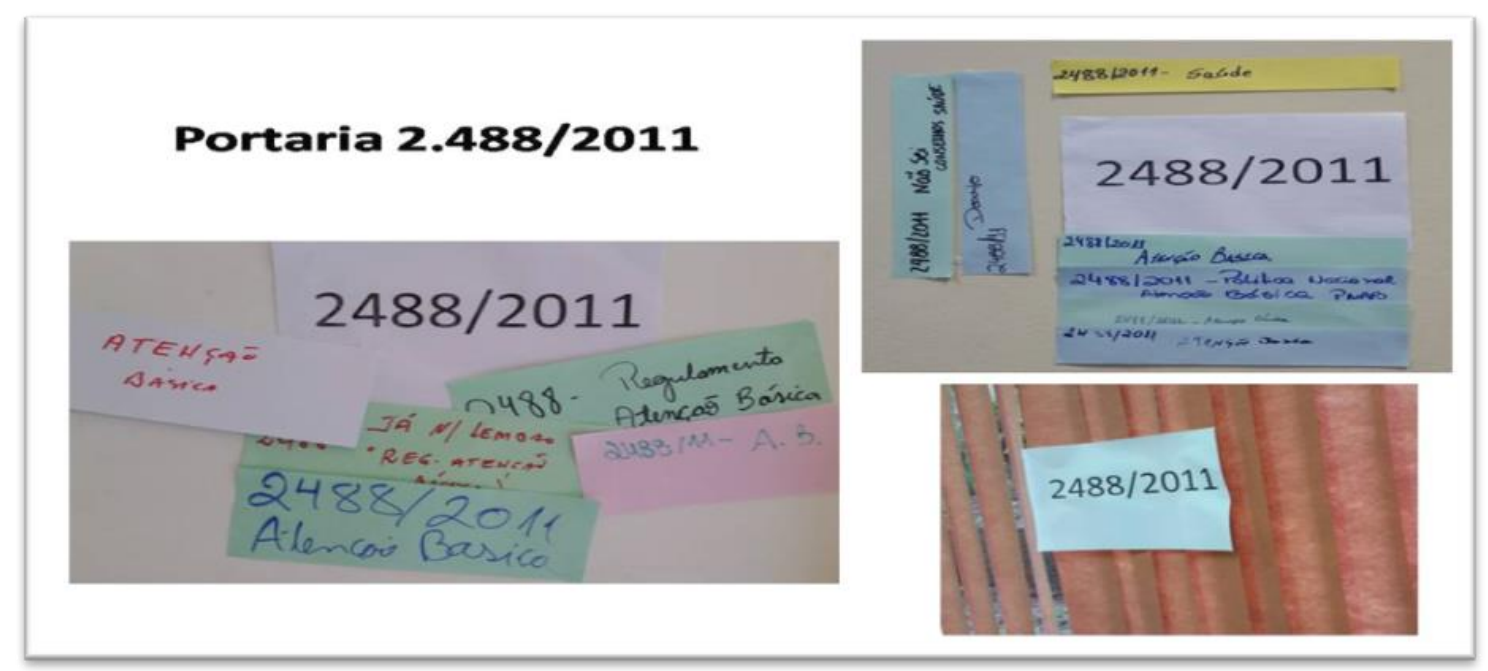

Figura 4: Conhecimento dos Conselheiros sobre a Portaria n 2.488/2011. Chapecó, SC, 2015.

Entretanto, na socialização em grupo, surgiram vários relatos referenciando a PNAB. Nesse sentido, é de conhecimento que a PNAB possui, entre suas responsabilidades, a de estimular a participação popular e o controle social em seu território de atuação (BRASIL, 2011).

A participação ou controle social instituído como um princípio do SUS garante a participação da população na formulação e controle das políticas públicas, através dos conselhos e conferências de saúde (COTTA; CAZAL; RODRIGUES, 2009), sendo assim, dentre as funções dos conselheiros encontra-se o exercício desse controle e a participação ativa e horizontalizada na gestão das políticas públicas de saúde.

Ao final dos três encontros desse módulo temático, percebeu-se uma relevante desinformação da maioria dos conselheiros acerca das bases legais do SUS. No entanto, foi possível identificar, minoritariamente, representantes com maior grau de politização que tem clareza da importância do seu papel na sociedade. As avaliações dos participantes evidenciaram que a adequação do método utilizado no processo de capacitação, linguagem clara/simples e participação ativa dos envolvidos, possibilitaram reflexões e troca de experiências a partir de suas vivências, bem como permitiram o esclarecimento de dúvidas. Ainda, identificou-se potencial para exercerem o papel de multiplicadores dos conteúdos abordados sobre o SUS, nos municípios de origem.

Neste sentido, a interação entre os segmentos da formação e do controle social em saúde permitiu significar as características locais, valorizar capacidades instaladas, desenvolver potencialidades existentes em cada realidade, estabelecer aprendizagem significativa, efetiva e criativa bem como desencadear e fortalecer a capacidade crítica. 
Bases legais do SUS no conselho municipal: um desafio para efetivar a gestão participativa na saúde

Cotta, Cazal e Rodrigues (2009) afirmam que conselheiros capacitados têm média mais elevada de intervenções nas reuniões e de articulação com sua base do que os conselheiros não capacitados. Os autores ressaltam também

[...] ampliar o processo de empoderamento dos diferentes atores locais para fortalecer o exercício do controle social, buscando conscientizar os Conselheiros Municipais de Saúde sobre sua função de representação social, e ainda promover o reconhecimento do conselho como espaço de manifestações de interesses plurais em busca do benefício de toda sociedade. (COTTA; CAZAL; RODRIGUES, 2009, p.434)

Dessa maneira, iniciativas de educação permanente como esta aqui relatada fortalecem a capacidade dos conselheiros municipais de saúde de tomar decisões com embasamento legal, contribuem com a qualificação dos processos e organizações para uma participação mais efetiva nestes espaços e fomentam o protagonismo no processo de controle social em políticas públicas de saúde (ROLIM; CRUZ; SAMPAIO, 2013).

\section{CONSIDERAÇÕES}

Por fim, constatou-se a necessidade desses atores estarem em constante processo de capacitação e aperfeiçoamento, em especial no que tange à legislação, o que implica de forma direta na sua responsabilidade na condição de conselheiro municipal de saúde.

Para que o controle social seja fortalecido e realizado com êxito, se fazem necessárias medidas de qualificação, bem como o oferecimento de condições adequadas para o exercício do mesmo.

De maneira geral, a metodologia utilizada no desenvolvimento da capacitação possibilitou a participação de todos os segmentos representativos (usuários, profissionais de saúde, prestadores de serviço e gestores). A aproximação com a legislação ampliou os conhecimentos em relação ao seu papel como conselheiro de saúde e o do próprio conselho municipal de saúde.

Enfatiza-se que, embora não seja necessário que os conselheiros dominem todo o conteúdo das legislações normativas, é preciso que saibam a que essas leis se referem e onde podem encontrá-las para que possam ampliar seu conhecimento sobre elas e fortalecer sua participação social.

À medida que o acesso às informações e suas diferentes abordagens se ampliam, aumentam as possibilidades de entendimento da situação e com isso os subsídios para defender posições de enfrentamento ou ainda para formular proposições de forma coerente.

Ainda, a atividade extensionista possibilitou às autoras maior aproximação e domínio da legislação normatizadora do controle social em saúde no Brasil, bem como (re)conhecer a 
Bases legais do SUS no conselho municipal: um desafio para efetivar a gestão participativa na saúde

realidade loco regional em relação à participação social nos conselhos gestores de políticas públicas na área da saúde. Além disso, possibilitou perceber as dificuldades enfrentadas por esses órgãos colegiados e verificar a necessidade de consolidar o compromisso da universidade com as Comissões de Integração Ensino-Serviço locais para a promoção contínua de cursos de capacitação para os conselheiros e sociedade civil interessada, com o objetivo de fortalecer e qualificar o exercício do controle/participação social nos espaços da gestão pública.

\section{REFERÊNCIAS}

BRASIL. Constituição da República Federativa do Brasil: promulgada em 05 de outubro de 1988. Brasília: Senado Federal, Centro Gráfico, 1988.

Lei 8.142, 28 de dezembro de 1990. Dispõe sobre a participação da comunidade na gestão do SUS e sobre as transferências intergovernamentais de recursos financeiros na área de saúde e dá outras providências. Brasília, 1990. Disponível em:

<http://www.conselho.saude.gov.br>. Acesso em: 05 dez. 2015

Ministério da Saúde. Conselho Nacional de Saúde. Política nacional de educação permanente para o controle social no Sistema Único de Saúde - SUS / Ministério da Saúde, Conselho Nacional de Saúde.Brasília: Ministério da Saúde, 2006. 20 p. (Série B. Textos Básicos em Saúde).

. Ministério da Saúde. Política Nacional de Educação Permanente em Saúde. Secretaria de Gestão do Trabalho e da Educação na Saúde, Departamento de Gestão da Educação em Saúde. - Brasília: Ministério da Saúde, 2009. (Série B. Textos Básicos de Saúde, Série Pactos pela Saúde 2006; v. 9).

Ministério da Saúde. Política Nacional da Atenção Básica. Brasília: 2011. (Série E. Legislação em Saúde) Disponível em:

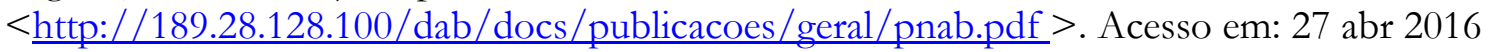

Resolução 453/2012, de 10 de maio de 2012, Dispõe sobre diretrizes para instituição, reformulação, reestruturação e funcionamento dos Conselhos de Saúde: disponível em $<$ http://conselho.saude.gov.br/ultimas noticias/2012/12 jun resolucao453.html > . Acesso em: 10 dez 2015.

COLLISELLI, Liane. A compreensão dos conselheiros municipais de saúde sobre a participação social e seus processos. Dissertação, UFSC. Florianópolis, 2009. 124 p.

CONSELHO NACIONAL DE SAÚDE. Sistema de Acompanhamento de Conselhos SIACS. Disponível em: < http://conselho.saude.gov.br/web siacs/demonstrativo.html $>$ Acesso em: 12 fev. 16.

COTTA, Rosângela Minardi Mitre; CAZAL, Mariana de Melo; RODRIGUES, Jôsi Fernandes de Castro. Participação, Controle Social e Exercício da Cidadania: a (des)informação como obstáculo à atuação dos conselheiros de saúde. Physis Revista de Saúde Coletiva, Rio de Janeiro, v. 19, n. 2, p. 419-38, 2009. 
Bases legais do SUS no conselho municipal: um desafio para efetivar a gestão participativa na saúde

FREIRE, Paulo. Pedagogia da autonomia: saberes necessário à prática educativa. São Paulo: Paz e Terra (Coleção Leitura). 25a Ed., 1996. Disponível em:

<http://www.apeoesp.org.br/sistema/ck/files/4-

\%20Freire P \%20Pedagogia\%20da\%20autonomia.pdf>. Acesso em: 04 jun. 2017.

FREITAS, Zenite da Graça Bogea; SOUTO, Kátia Maria Barreto; BONETTI, Oswaldo Peralta.O programa de inclusão digital (pid): fortalecimento dos conselhos de saúde do Brasil. V Congresso CONSAD. Brasília, 2012.

KLEBA, Maria Elisabeth; ZAMPIROM, Keila; COMERLATTO, Dunia. Processo decisório e impacto na gestão de políticas públicas: desafios de um Conselho Municipal de Saúde. Saúde Soc. São Paulo, v.24, n.2, p.556-67, 2015.

PAIM, Jairnilson Silva. A reforma sanitária e o CEBES. Projeto Formação em cidadania para saúde: temas fundamentais da reforma sanitária. Rio de Janeiro: CEBES, 2012. 28p.

POLIGNANO, Marcos Vinicius. História das políticas de saúde no Brasil: uma pequena revisão. s/d. Disponível em: < http://www.saude.mt.gov.br/upload/documento/16/historia-daspoliticas-de-saude-no-brasil-\%5B16-030112-SES-MT\%5D.pdf>. Acesso em: 29 out. 2015.

ROCHA, Carlos Vasconcelos. Gestão pública municipal e participação democrática no Brasil. Rev. Sociol. Polít., Curitiba, v. 19, n. 38, p. 171-185, fev. 2011.

ROLIM, Leonardo Barbosa; CRUZ, Rachel de Sá Barreto Luna Callou; SAMPAIO, Karla Jimena Araújo de Jesus. Participação popular e o controle social como diretriz do SUS: uma revisão narrativa. Saúde em Debate. Rio de Janeiro, v. 37, n. 96, p. 139-47. Jan/mar, 2013.

SANTA CATARINA. Plano estadual de educação permanente Santa Catarina- 2010/2013: Diretrizes para a implementação da Política Nacional de Educação Permanente em Saúde no Estado de Santa Catarina. Florianópolis: Secretaria do Estado da Saúde/ Diretoria de Educação Permanente em Saúde. p. 1-74, 2009. Disponível em:

$<\underline{\text { https: } / / \text { www.google.com.br/url? sa }=\text { t\&rct }=j \& q=\& e s r c=\text { s\&source }=\text { web\&cd }=1 \& v e d=0 a h U K E}$ wiK8qah0 LKAhWMEJAKHYBIDgQFggdMAA\&url=http $\% 3 \mathrm{~A} \% 2 \mathrm{~F} \% 2 \mathrm{Fportalses}$.saude.sc.gov.br $\% 2$ Findex.php $\% 3$ Foption $\% 3 \mathrm{Dco}$ $\mathrm{m}$ docman $\% 26 \operatorname{task}^{2} 3$ Ddoc download $\% 26 \mathrm{gid} \% 3 \mathrm{D} 2869 \% 26$ Itemid $\% 3 \mathrm{D} 82$ \&usg $=$ AFQjCNGi NDQz0XfTQH4dlvhKhoI9z8oBdQ\&sig2=KL6yJj6EHl0RwppMhkO69w > Acesso em: 12 fev. 2016. 